\title{
Benralizumab in the treatment of severe asthma: design, development and potential place in therapy
}

This article was published in the following Dove Press journal:

Drug Design, Development and Therapy

\author{
Corrado Pelaia' \\ Alessandro Vatrella ${ }^{2}$ \\ Andrea Bruni' \\ Rosa Terracciano ${ }^{3}$ \\ Girolamo Pelaia' \\ 'Department of Medical and Surgical \\ Sciences, Section of Respiratory \\ Diseases, "Magna Græcia” University \\ of Catanzaro, Catanzaro, Italy; \\ ${ }^{2}$ Department of Medicine, Surgery \\ and Dentistry, Section of Respiratory \\ Diseases, University of Salerno, \\ Salerno, Italy; ${ }^{3}$ Department of Health \\ Sciences, "Magna Græcia” University \\ of Catanzaro, Catanzaro, Italy
}

\begin{abstract}
Asthma is a widespread and heterogeneous inflammatory disease of the airways, which is characterized by several different phenotypes and endotypes. In particular, eosinophilic airway inflammation is a common pathologic trait of both allergic and nonallergic asthma. The key cytokine responsible for maturation, activation, recruitment, and survival of eosinophils is interleukin (IL)-5, which is mainly produced by Thelper 2 (Th2) lymphocytes and group 2 innate lymphoid cells. Therefore, for uncontrolled patients with severe eosinophilic asthma, who are not fully responsive to corticosteroids, IL-5 represents a very important molecular target for add-on biological therapies. Among these new treatments, anti-IL-5 monoclonal antibodies such as mepolizumab and reslizumab have been developed and clinically evaluated. Furthermore, benralizumab is currently the only available biologic drug that specifically binds to the IL-5 receptor, thus preventing the interaction with its ligand and the consequent pro-inflammatory effects. The effectiveness of benralizumab in improving severe eosinophilic asthma has been well-documented by many randomized controlled trials.
\end{abstract}

Keywords: IL-5, IL-5 receptor, severe eosinophilic asthma, benralizumab

\section{Introduction}

Asthma is a chronic obstructive disease of the airways, characterized by wheezing, shortness of breath, cough, and chest tightness, caused by airflow limitation due to inflammatory and structural changes. ${ }^{1,2}$ Airway inflammation in asthma can be driven by either type- 2 mechanisms mainly sustained by T helper 2 (Th2)/group 2 innate lymphoid cells (ILC2) cells and leading to bronchial eosinophilia, or by nontype-2 pathways mediated by Th1 and especially Th17 lymphocytes, responsible for neutrophilic infiltration of the airways. ${ }^{3}$ With respect to non-type-2 neutrophilic inflammation, type-2 eosinophilic asthma is usually more responsive to pharmacologic treatment. Inhaled corticosteroids (ICS) are the mainstay of asthma therapy, and they powerfully induce eosinophil apoptosis. In particular, these drugs exert a pro-apoptotic effect by inhibiting the synthesis of key survival factors for eosinophils, including interleukin (IL)-5, IL-3 and granulocyte macrophage colony stimulating factor (GM-CSF). ${ }^{4,5}$ However, a subgroup of patients with eosinophilic asthma are not fully responsive to corticosteroids, thus experiencing frequent exacerbations and an overall difficult-to-treat disease, not adequately controlled by high doses of standard therapies. It is thus possible that, in these subjects, type- 2 inflammation increases to such a great extent that it leads to an excessive release of IL-5, which makes eosinophils less sensitive to corticosteroids. ${ }^{6}$ Indeed, the apoptotic action of corticosteroids is completely lost when eosinophils are exposed to high concentrations of IL- $5 .^{7}$
Correspondence: Girolamo Pelaia Campus Universitario "S. Venuta", Viale Europa-Località Germaneto, Catanzaro 88100, Italy

Tel $+39096|3647| 7 \mid$

Fax +3909613647193

Email pelaia@unicz.it 
These observations imply that IL-5 plays a central role in inducing, maintaining and amplifying eosinophilic asthma driven by type- 2 inflammation. The main cellular sources of IL-5 include CD4 + Th2 lymphocytes and ILC2 cells and, to a lesser extent, also CD8 + type-2 (Tc2) cells, mast cells, and eosinophils themselves. ${ }^{8-13} \mathrm{Th} 2$ lymphocytes produce IL-5 in response to a complex activation process involving antigen-presenting dendritic cells, IL-4, and the transcription factor GATA3, whereas ILC2 are primed to synthesize IL-5 by airway epithelium-derived innate cytokines IL-25, IL-33, and thymic stromal lymphopoietin, also via engagement of GATA3. ${ }^{1,2,14}$ IL-5 stimulates eosinophil maturation in the bone marrow, enhances eosinophil survival, and promotes the recruitment of eosinophils into the airways. ${ }^{15}$ Therefore, IL-5 is a suitable target for add-on biological therapies of severe eosinophilic asthma. ${ }^{16,17}$ In particular, 3 humanized monoclonal antibodies have been developed and extensively evaluated for treatment of refractory eosinophilic asthma: these drugs include the anti-IL-5 antibodies mepolizumab and reslizumab, and the IL-5 receptor antagonist benralizumab. ${ }^{18-24}$

Based on the above-mentioned considerations, the aims of the present review article are to discuss the mechanisms underlying the biological activity of IL- 5 and its inhibition by benralizumab, and to outline the main clinical trials that have documented the effectiveness of benralizumab in the treatment of severe eosinophilic asthma.

\section{IL-5: mechanism of action}

IL-5 is a disulfide-linked homodimer (molecular weight: $50-60 \mathrm{kDa}$ ) that binds to a membrane receptor expressed by eosinophils and basophils and consisting of 2 subunits named $\alpha$ (molecular weight: $60 \mathrm{kDa}$ ) and $\beta \mathrm{c}$ (molecular weight: $130 \mathrm{kDa}$ ), respectively. ${ }^{25-27}$ The $\alpha$ subunit (IL-5R $\alpha$ ) specifically recognizes IL-5, whereas the nonspecific $\beta \mathrm{c}$ chain can interact not only with IL-5, but also with IL-3 and GM-CSF. ${ }^{15,28,29}$ High-affinity binding of IL-5 to IL-5R $\alpha$ triggers the interaction between $\alpha$ and $\beta c$ receptor subunits, and such a dimerization process leads to tyrosine phosphorylation-dependent activation of IL-5R $\alpha$-associated Janus kinase 2 (JAK2), which, in turn, activates signal transducers and activators of transcription 1, 3 and 5 (Figure 1). ${ }^{30,31}$ The latter are responsible for transcriptional activation of some genes involved in eosinophil proliferation, including pim-1 and cyclin D3. ${ }^{30,31}$ Moreover, together with Lyn and Raf-1 kinases, JAK2 contributes towards mediating the powerful survival effect induced by IL-5 in eosinophils, which is due to inhibition of cell apoptosis. ${ }^{32}$ Indeed, high numbers of eosinophils have been detected in bronchial biopsies, induced sputum, and peripheral blood of subjects with asthma driven by type- 2 inflammation. ${ }^{33-35}$ Raf-1 also stimulates eosinophil degranulation, ${ }^{32}$ resulting in the release of granule content consisting of cytotoxic proteins including major basic protein, eosinophil cationic protein, eosinophil peroxidase, and eosinophil-derived neurotoxin, ${ }^{36,37}$ which cause airway epithelial damage.

In the signal transduction network activated by IL-5, a central role is also played by other kinases such as mitogenactivated protein kinases (MAPK) and phosphoinositide 3-kinase (PI3K) (Figure 1). In particular, Raf-1-mediated activation of the extracellular signal-regulated kinases (ERK) subfamily of MAPK induces eosinophil differentiation, survival and proliferation, ${ }^{38-42}$ as well as the release of leukotriene $\mathrm{C}_{4}$, which, in turn, behaves as a powerful chemoattractant for eosinophils themselves. ${ }^{43}$ Furthermore, through activation of the transcription factor nuclear factor- $\mathrm{\kappa B}$, the p38 subfamily of MAPK elicits eosinophil infiltration of the airways in allergic inflammation, and also facilitates eosinophil production of pro-inflammatory cytokines. ${ }^{44,45}$ In addition, via PI3K-dependent stimulation of ERK $1 / 2$ and protein kinase $\mathrm{C}$, IL-5 promotes the interaction of eosinophils with intercellular adhesion molecule-1 ${ }^{46}$ thus further contributing to eosinophil recruitment into inflamed tissues.

\section{Benralizumab: development and mechanism of action}

Benralizumab, previously named MEDI-563, was developed by AstraZeneca/MedImmune (Gaithersburg, MA, USA) through hybridoma technology. ${ }^{47-49}$ It is a humanized IgG1k monoclonal antibody of murine origin, which specifically binds to the amino acid isoleucine- 61 present within the domain 1 of human IL-5R $\alpha$, thus interacting with the extracellular IL-5R $\alpha$ epitope, which is located very close to the IL-5 binding site. ${ }^{50,51}$ As a consequence, benralizumab inhibits hetero-dimerization of IL-5 receptor $\alpha / \beta$ c subunits and the following signal transduction mechanisms.

In addition to interacting with IL-5R $\alpha$ via its Fab fragments, benralizumab is also capable of binding through the constant Fc region to the FcyIIIa receptor, expressed on the surface of natural killer (NK) cells (Figure 2), macrophages, and neutrophils..$^{52,53}$ In particular, benralizumab was generated in Chinese hamster ovary cells that lacked the enzyme $\alpha-1,6$-fucosyltransferase. The consequent absence of the fucose sugar residue in the oligosaccharide core of the $\mathrm{CH} 2$ domain of the constant region of benralizumab induces a 5- to 50-fold increase in the antibody affinity for the FcyRIIIa receptor. ${ }^{51}$ Hence, with respect to the parental fucosylated 


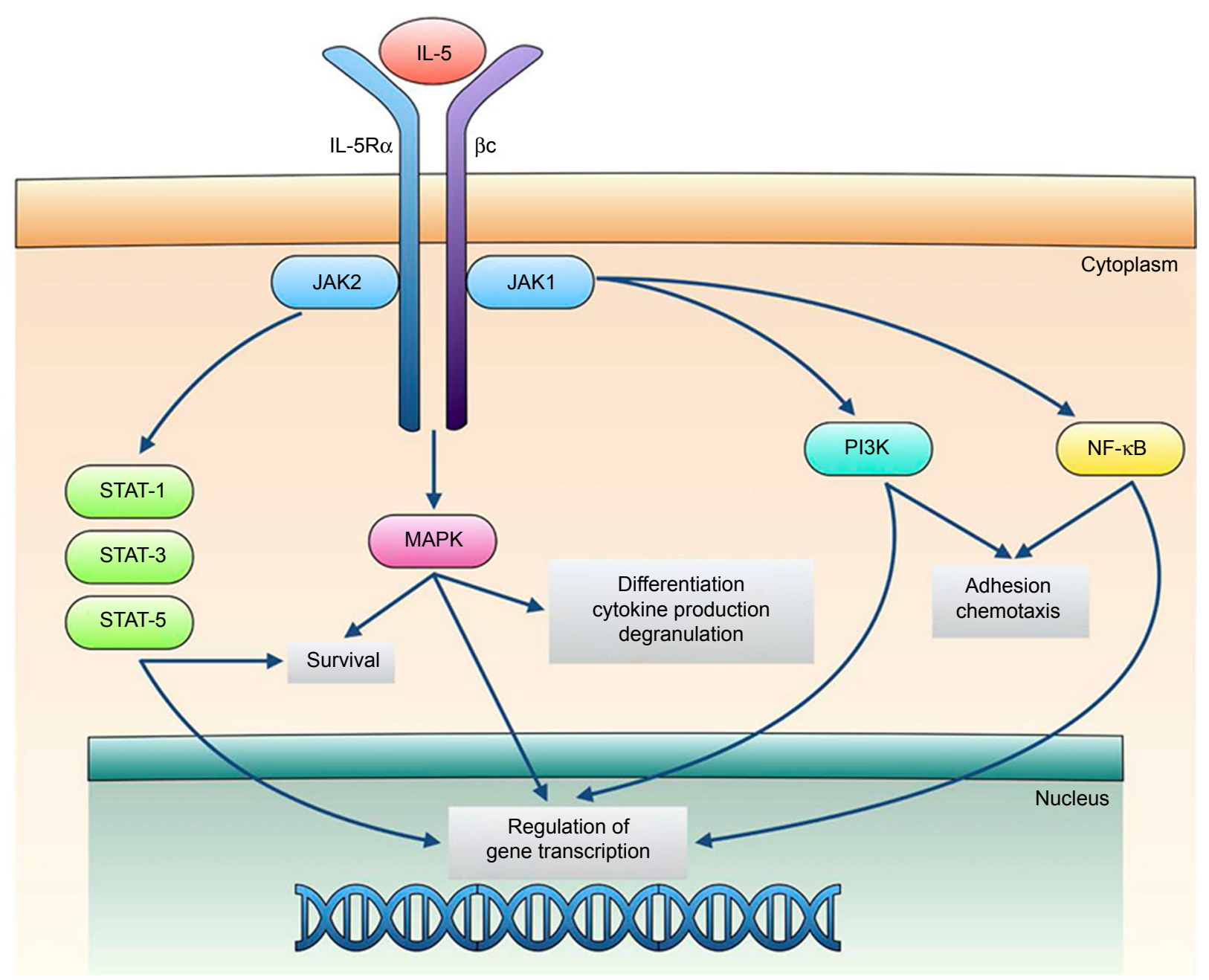

Figure I Signaling network activated by IL-5 in eosinophils.

Notes: Binding of IL-5 to the $\alpha$ subunit of the IL-5 receptor (IL-5R $\alpha$ ) promotes the heterodimerization of IL-5R $\alpha$ and $\beta \mathrm{c}$ subunits. As a consequence, many signal transduction pathways are activated, including JAK/STAT modules, MAPK, PI3K and NF- $\mathrm{BB}$. The combined stimulation of these kinases and transcription factors drives the expression of key genes responsible for differentiation, survival, degranulation, adhesion, and recruitment of eosinophils. Copyright @2017. Dove Medical Press. Reproduced from Pelaia C, Vatrella A, Busceti MT, et al. Severe eosinophilic asthma: from the pathogenic role of interleukin-5 to the therapeutic action of mepolizumab. Drug Des Devel Ther. 2017;|I:3|37-3|44.22

Abbreviations: IL, interleukin; JAK, janus kinase; MAPK, mitogen-activated protein kinases; NF, nuclear factor; PI3K, phosphoinositide 3-kinase; STAT, signal transducers and activators of transcription.

antibody, afucosylation is responsible for a $\geq 1,000$-fold amplification of the mechanism called antibody-dependent cell-mediated cytotoxicity (ADCC), resulting in apoptosis of eosinophils and basophils caused by NK cells via the release of pro-apoptotic proteins such as perforin and granzyme. ${ }^{51}$ Indeed, benralizumab enhanced eosinophil staining with the apoptotic marker annexin $\mathrm{V} .{ }^{51}$

Therefore, benralizumab strikes a dual deadly blow against eosinophils because it neutralizes the key survival signal for these cells provided by IL-5, and also directly activates FcyRIIIa-induced ADCC, driven by NK cells (Figure 2). Through these very effective mechanisms, benralizumab prompts a rapid eosinophil depletion in asthmatic patients, mainly dependent on inhibition of eosinophil maturation and survival in both bone marrow and inflamed tissues. ${ }^{52,53}$
Indeed, these powerful actions of benralizumab induce a sharp decrease of peripheral blood eosinophils, associated with a nearly complete elimination of airway eosinophils. ${ }^{15}$

\section{Benralizumab: clinical trials in asthma}

Many Phase I, II, and III clinical trials have clearly shown the high efficacy and good tolerability of benralizumab in patients with eosinophilic asthma.

In an initial Phase I, dose-rising study performed by Busse et al, pharmacokinetics and pharmacodynamics of benralizumab were assessed by monitoring blood eosinophil levels over 12 weeks after administration of single, intravenous drug dosages included within a range of $0.0003-3 \mathrm{mg} / \mathrm{kg}$, to patients with mild asthma. ${ }^{54}$ Benralizumab persistently and dose-dependently depleted peripheral blood eosinophils. 


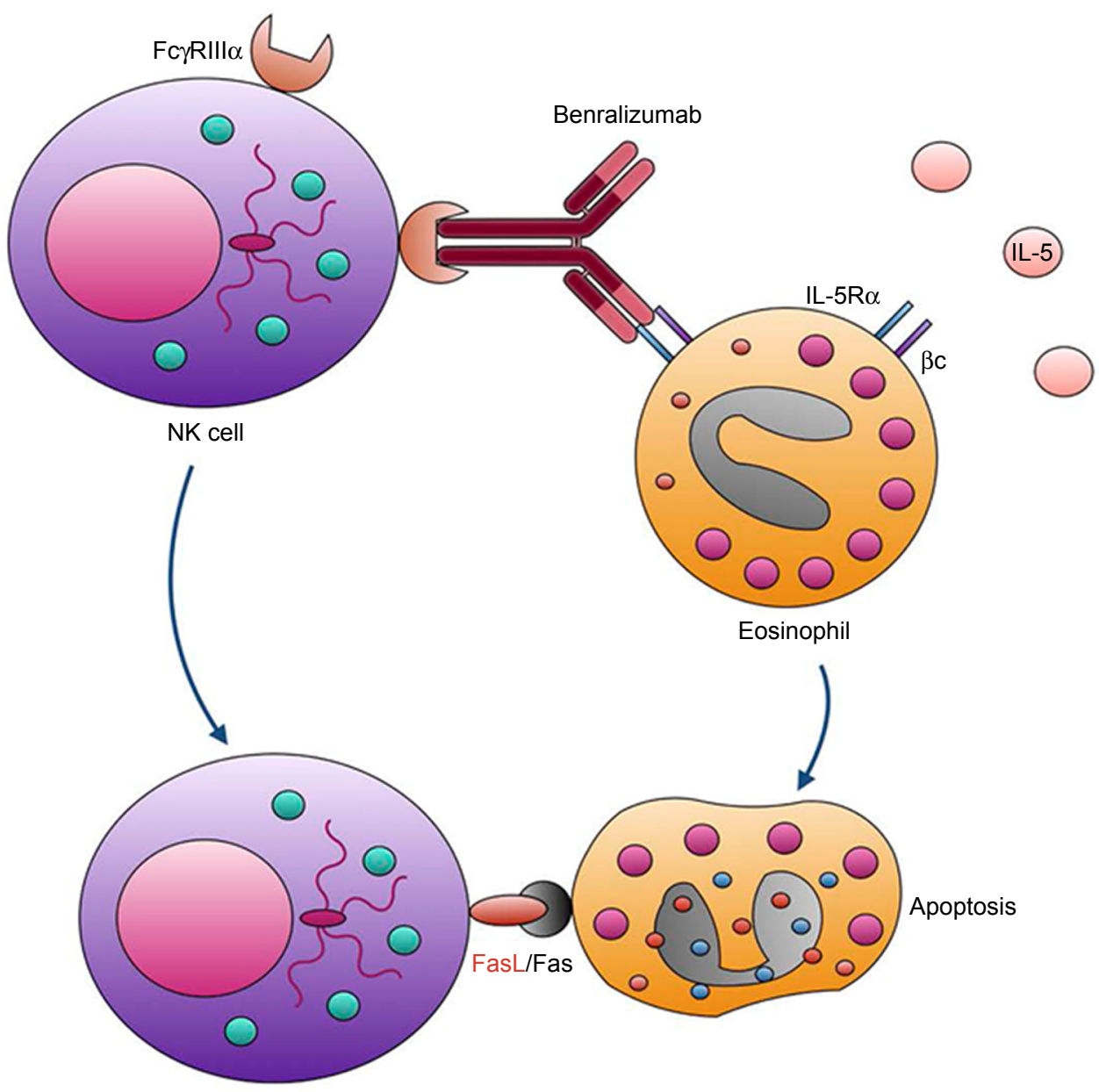

Figure 2 Mechanisms of action of benralizumab.

Notes: Benralizumab is a humanized monoclonal antibody characterized by a dual mechanism of action. In particular, through the Fab fragments, benralizumab binds to IL-5R $\alpha$, thus inhibiting the interaction between IL-5 and its receptor. Moreover, via the Fc constant region, benralizumab interacts with the Fc $\gamma$ llIRa receptor expressed by NK cells, thereby triggering ADCC-induced apoptosis of eosinophils, mediated by Fas/Fas ligand-dependent mechanisms.

Abbreviations: ADCC, antibody-dependent cell-mediated cytotoxicity; IL-5, interleukin-5; NK, natural killer.

In particular, benralizumab-induced eosinopenia lasted at least 8 and 12 weeks with doses of $0.03-0.1$ and $0.3-3 \mathrm{mg} / \mathrm{kg}$, respectively, whereas blood eosinophil counts were not lowered by dosages ranging from 0.0003 to $0.003 \mathrm{mg} / \mathrm{kg}$. At doses of $0.03-3 \mathrm{mg} / \mathrm{kg}$, the mean maximum concentration (1-82 $\mu \mathrm{g} / \mathrm{mL})$ was approximately dose-proportional. The mean volume of distribution $(52-93 \mathrm{~mL} / \mathrm{kg}$ ) of benralizumab was larger than the plasma volume, thereby indicating a possible binding to IL-5R $\alpha$-expressing blood cells, as well as a moderate penetration into extravascular tissues. The mean elimination half-life was $\sim 2-3$ weeks, which is typical of human IgG antibodies.

A subsequent Phase I, multicentre, randomized, doubleblind, and placebo-controlled study was conducted by Laviolette et al, and completed by 26 asthmatic patients, recruited on the basis of a documented bronchial hyperresponsiveness or reversible airway obstruction. ${ }^{55} \mathrm{~A}$ single intravenous dose of $1 \mathrm{mg} / \mathrm{kg}$ of benralizumab was administered to 8 patients, who were compared with 5 placebo-treated subjects. Furthermore, 3 monthly subcutaneous doses of placebo, 200 and $100 \mathrm{mg}$ of benralizumab were delivered to 4,5 , and 4 patients, respectively. Bronchoscopies with airway mucosal/submucosal biopsies were performed at baseline, and 28 days after the end of treatment, with the aim of examining tissue eosinophils. Moreover, blood samples were taken to measure peripheral eosinophil counts. In a subgroup of patients, eosinophils were also analyzed in induced sputum and bone marrow biopsies. After treatments with either intravenous or subcutaneous benralizumab, circulating eosinophils were not detectable anymore. There was also complete depletion of eosinophils and eosinophil precursors in the bone marrow. In comparison to placebo, benralizumab also reduced eosinophil numbers in induced sputum and airway mucosal/submucosal biopsies; however, 
these decreases did not reach the threshold of statistical significance for each independent dosing. Therefore, such results suggest that while benralizumab was able to completely suppress the production of eosinophils in the bone marrow, thus effectively removing these cells from bloodstream, the drug was less effective on eosinophils that had already reached the airways. Hence, it can be speculated that tissue eosinophils are possibly at a more advanced maturation stage, which makes them less susceptible to pharmacological treatments, also including anti-IL-5/IL-5R therapies. ${ }^{56}$

A Phase IIa trial was later performed by Park et al in patients having $\geq 2 \%$ sputum eosinophils or $\mathrm{FeNO} \geq 50$ parts per billion, who had experienced 2-6 asthma exacerbations in the previous year, despite the use of medium/high doses of ICS and long-acting $\beta_{2}$-adrenergic agonists (LABA). ${ }^{57}$ One hundred and six subjects were randomly subdivided into 4 groups, assigned to receive subcutaneous injections of placebo $(\mathrm{n}=27)$ and benralizumab at dosages of $2 \mathrm{mg}$ $(\mathrm{n}=27), 20 \mathrm{mg}(\mathrm{n}=26)$, and $100 \mathrm{mg}(\mathrm{n}=26)$, respectively. Placebo or drug administrations were made on weeks 0 (day 1), 4, 8, 16, 24, 32, and 40. Compared with placebo, at week 52 , benralizumab reduced the annual exacerbation rates by $33 \%, 45 \%$, and $36 \%$ when used at doses of 2, 20 and $100 \mathrm{mg}$, respectively. Furthermore, forced expiratory volume in 1 second $\left(\mathrm{FEV}_{1}\right)$ improved throughout the study period at all dosages of benralizumab, reaching the highest increases at week 52 after the $100 \mathrm{mg}$ dose, especially in subjects with a blood eosinophil count $\geq 300$ cells $/ \mu \mathrm{L}$ (mean $\mathrm{FEV}_{1}$ increase: $28.1 \%$ ). This drug also induced a marked decrease in peripheral blood eosinophil numbers. The safety profiles of all benralizumab doses were acceptable and did not significantly differ from placebo. ${ }^{57}$

Benralizumab was also tested in a Phase IIb randomized, dose-ranging trial, carried out by Castro et al in patients with uncontrolled asthma. ${ }^{58}$ This study was completed by 324 eosinophilic and 282 non-eosinophilic uncontrolled asthmatic patients who had experienced 2-6 asthma exacerbations during the previous year, despite regular treatment with medium-high doses of ICS/LABA. Of the 324 eosinophilic subjects, 80 were randomly assigned to treatment with placebo, whereas the remaining, 81,81 , and 82 participants received 2, 20 and $100 \mathrm{mg}$ of benralizumab, respectively. With regard to 282 non-eosinophilic patients, 142 received placebo and 140 were given $100 \mathrm{mg}$ of benralizumab. Study drugs were administered as 2 subcutaneous injections every 4 weeks for the first 3 doses (weeks 1, 4, and 8), and then every 8 weeks (weeks 16, 24, 32, and 40). In comparison to placebo, at week 52 , the annual rates of asthma exacerbations were found to be lower in eosinophilic subjects receiving $100 \mathrm{mg}$, but not 20 or $2 \mathrm{mg}$ of benralizumab. This drug was more effective in decreasing exacerbations when blood eosinophil counts were $\geq 300$ cells $/ \mu \mathrm{L}$. In these same patients, asthma exacerbations were reduced by benralizumab at both dosages of 100 and $20 \mathrm{mg}$. In non-eosinophilic individuals, $100 \mathrm{mg}$ of benralizumab did not change the annual rate of asthma exacerbations. In eosinophilic asthmatics, all benralizumab doses decreased blood eosinophil counts, improved asthma control, and increased $\mathrm{FEV}_{1}$ values. Mild-to-moderate adverse events were slightly more frequent in benralizumab groups than in the placebo arm, with nasopharyngitis and local reactions at injection sites being the most commonly reported manifestations.

A further Phase II study was conducted by Nowak et al who evaluated the effects of a single intravenous infusion of benralizumab added to current standard treatments prescribed at discharge from emergency department on recurrence of asthma exacerbations and/or on hospitalization for acute asthma. ${ }^{59}$ This trial was completed by 3 subject groups, each consisting of 36 patients who randomly received placebo (first group) or benralizumab $0.3 \mathrm{mg} / \mathrm{kg}$ (second group) or $1.0 \mathrm{mg} / \mathrm{kg}$ (third group). The enrolled participants were chosen because, in addition to the occurrence of at least 1 previous exacerbation requiring an urgent care visit during the past 12 months, they presented to an emergency department for acute asthma, and experienced only a partial response to treatment. Compared with placebo, the effects induced by benralizumab 12 weeks after drug administration resulted in significant $49 \%$ and $60 \%$ reductions of asthma exacerbations rates and exacerbations leading to hospitalization, respectively. At the same time-point, such findings were paralleled by marked decreases in blood eosinophil numbers, as well as in serum levels of eosinophilic cationic protein (ECP) and eosinophil-derived neurotoxin (EDN), which are important markers of cell activation. All these effects were observed after injection of both 0.3 and $1.0 \mathrm{mg} / \mathrm{kg}$ doses of benralizumab. This drug displayed a good safety profile. Indeed, only mild-to-moderate and self-limiting adverse events were observed, including headache, dizziness, cough, fever, bronchitis, anxiety, muscle spasms, and hyperhidrosis. At week 12, anti-benralizumab antibodies were detected in 6 patients, who, however, did not experience any clinical consequence. The ability of benralizumab to significantly lower the serum levels of ECP and EDN was also confirmed by Pham et al, ${ }^{60}$ and these findings further corroborate the speculation that benralizumab not only reduces the peripheral blood counts of eosinophils, but also impairs their 
ability to release the cytotoxic protein content of cytoplasmic granules. ${ }^{24}$

With regard to add-on biological treatment of severe eosinophilic asthma, the positive results of several Phase III clinical trials provided very robust evidence which made it possible for benralizumab to recently obtain the approval from the US Food and Drug Administration. In particular, the WINDWARD program consists of 6 Phase III studies, including SIROCCO, CALIMA, ZONDA, BORA, BISE, and GREGALE, designed to evaluate the efficacy and safety of benralizumab in large populations of severe asthmatics. ${ }^{24}$

Among 2,681 patients treated with high doses of ICS/ LABA and enrolled in the SIROCCO trial, 1,205 subjects met the inclusion criteria and were randomized to receive for 48 weeks 1 of 3 add-on subcutaneous treatments, according to the following scheme; 407 participants were assigned to the placebo arm; 400 patients received benralizumab $30 \mathrm{mg}$ every 4 weeks (Q4W); 398 asthmatics were treated with benralizumab $30 \mathrm{mg}$ every 8 weeks $(\mathrm{Q} 8 \mathrm{~W}) .{ }^{61}$ Compared with placebo, at week 48 , the annual rates of asthma exacerbations were found to be reduced by $45 \%$ and $51 \%$ in Q4W and Q8W subgroups with $\geq 300$ blood eosinophils $/ \mu \mathrm{L}$, respectively. Interestingly, the annual exacerbation rate decreased by $17 \%-30 \%$ in patients with $<300$ blood eosinophils $/ \mu \mathrm{L}$. Moreover, when compared to placebo, at week 48 , both benralizumab dosages significantly improved pre-bronchodilator $\mathrm{FEV}_{1}$, whose mean increases with respect to baseline were 106 and $159 \mathrm{~mL}$ in Q4W and Q8W regimens, respectively. Asthma symptoms improved only in the Q8W cohort. The most frequently observed adverse events included asthma worsening, occurring in 13\% of benralizumab-treated patients and in $19 \%$ of placebo-treated subjects, and nasopharyngitis, reported by $12 \%$ of both benralizumab-treated and placebotreated patients.

Similar to SIROCCO, the CALIMA study also enrolled asthmatic patients uncontrolled by medium-to-high dosages of ICS/LABA, experiencing 2 or more exacerbations during the previous year. ${ }^{62}$ Among 2,505 recruited subjects, 1,306 were randomized according to the same criteria of the SIROCCO trial. Therefore, for 56 weeks, 440 patients were treated with placebo, whereas 425 and 441 participants received subcutaneous injections of benralizumab $30 \mathrm{mg}$ Q4W and Q8W, respectively. Compared with placebo, Q4W and Q8W regimens significantly decreased the annual rates of asthma exacerbations by $36 \%$ and $28 \%$, respectively. Moreover, in patients with $\geq 300$ blood eosinophils $/ \mu \mathrm{L}, \mathrm{Q} 4 \mathrm{~W}$ and Q8W schedules elicited mean increases in pre-bronchodilator $\mathrm{FEV}_{1}$ of 125 and $116 \mathrm{~mL}$, respectively. In addition, both benralizumab treatments dramatically lowered blood eosinophil counts, while only the $\mathrm{Q} 8 \mathrm{~W}$ regimen improved the total asthma symptom score. The most common adverse events included nasopharyngitis (21\% in the Q4W group, $18 \%$ in the Q8W cohort, and 21\% in the placebo arm) and asthma worsening (14\% in the Q4W group, $11 \%$ in the Q8W cohort, and $15 \%$ in the placebo arm).

The primary aim of the ZONDA study was to evaluate, in patients with severe asthma, the sparing effect of benralizumab on the intake of oral corticosteroids. ${ }^{63}$ Two hundred and twenty subjects were randomized to subcutaneously receive Q4W or Q8W for 28 weeks either placebo or $30 \mathrm{mg}$ of benralizumab. With respect to baseline, the median final oral doses of corticosteroids decreased by $75 \%$ and $25 \%$ in benralizumab and placebo groups, respectively. Furthermore, in comparison to placebo, the annual rates of asthma exacerbations were found to be reduced by $55 \%$ and $70 \%$ in Q4W and Q8W benralizumab subgroups, respectively. With regard to $\mathrm{FEV}_{1}$, no significant differences were detected between benralizumab and placebo cohorts. Benralizumab and placebo induced similar patterns of adverse events, mostly consisting of nasopharyngitis, asthma worsening, and bronchitis.

The BORA study (ClinicalTrials.gov Identifier: NCT02258542) is evaluating the safety and tolerability profile of benralizumab in asthmatic patients under treatment with ICS/LABA combinations, who have already completed one of the previous 3 studies (SIROCCO, CALIMA or ZONDA). The enrolled subjects who will complete at least 16 weeks of the study, without exceeding 40 weeks, will have the possibility of participating in a further safety extension trial (MELTEMI-ClinicalTrials.gov Identifier: NCT02808819), and will be monitored for 2 more years.

The BISE trial was completed by 211 participants with mild-to-moderate persistent asthma, treated with low-tomedium ICS dosages and randomly assigned to receive subcutaneous injections of either placebo or benralizumab $30 \mathrm{mg}$ Q4W for 12 weeks. ${ }^{64}$ When compared to placebo at week 12, an $80 \mathrm{~mL}$ increase in pre-bronchodilator $\mathrm{FEV}_{1}$ was found in subjects treated with benralizumab. FEV changes were not different between patient subgroups having baseline numbers of blood eosinophils higher or lower than $300 / \mu \mathrm{L}$. Anyway, in the benralizumab group, at week 12 , the median blood eosinophil count was found to be 0 cells $/ \mu \mathrm{L}$ (range: 0-110), which was different from the placebo arm at the same time as it was characterized by the presence of a median value of 230 blood eosinophils/ $\mu \mathrm{L}$ (range: 30-1,000); benralizumab-dependent depletion of blood 
eosinophils persisted up to week 20. For patients assigned to benralizumab and placebo cohorts, similar incidences were reported with regard to adverse events, mainly including nasopharyngitis, upper respiratory tract infections, asthma worsening, and headache.

The GREGALE open-label study, which recruited 116 patients with severe asthma, has recently shown that a very large majority of the subjects or their family members were able to successfully inject at home, through the subcutaneous route, $30 \mathrm{mg}$ of benralizumab using an accessorized prefilled syringe. ${ }^{24}$

A recent meta-analysis that included 1,951 asthmatic patients participating in 5 Phase I/II/III studies among the above-mentioned trials has shown that, compared with placebo, benralizumab significantly improved the scores of both asthma control questionnaire- 6 and asthma quality of life questionnaire, increased $\mathrm{FEV}_{1}$, and reduced the annual rate of asthma exacerbations. ${ }^{65}$ Furthermore, this meta-analysis demonstrated that the dosing regimen of benralizumab $30 \mathrm{mg}$ Q8W was more effective than the same dosage administered Q4W. Moreover, no significant differences were found between benralizumab and placebo with regard to the occurrence of adverse events.

In addition to the 6 trials of the WINDWARD program, other Phase III studies that are still ongoing include SOLANA, ANDHI, and MIRACLE. ${ }^{24}$ SOLANA (ClinicalTrials.gov Identifier: NCT02869438) is currently assessing, in patients with severe eosinophilic asthma, the effects of benralizumab on symptom control, lung function, blood eosinophils, and quality of life. The ANDHI trial (ClinicalTrials.gov Identifier: NCT03170271) has been designed to investigate, in subjects with severe eosinophilic asthma, the impact of benralizumab on the rate of asthma exacerbations, as well as on lung function and quality of life. Moreover, a subgroup of participants in this study will also undergo evaluation for some important asthma comorbidities, including chronic rhinosinusitis and nasal polyposis. In addition to
ANDHI, the MIRACLE trial (ClinicalTrials.gov Identifier: NCT03186209) also aims primarily to study, in patients with severe uncontrolled asthma under treatment with mediumto-high doses of ICS/LABA combinations, the effects of benralizumab on the annual rate of asthma exacerbations.

The main pre-marketing clinical trials evaluating the effects of benralizumab in the treatment of eosinophilic asthma are summarized in Table 1.

\section{Benralizumab: potential place in the treatment of severe asthma}

Although many patients with eosinophilic asthma usually benefit from treatment with ICS, some subjects expressing the most severe phenotypes of type-2 airway inflammation cannot be adequately controlled by inhaled and even systemic corticosteroids. In this regard, because of the central role played by IL-5 in promoting, prolonging, and expanding eosinophilic inflammation, this cytokine and its receptor represent suitable molecular targets of add-on biological treatments for severe type- 2 asthma. Within such a context, by virtue of its peculiar mechanisms of action, benralizumab can potentially be more effective than antiIL-5 monoclonal antibodies (mepolizumab and reslizumab) in inducing eosinophil depletion. Indeed, the combination of IL-5R $\alpha$ blockade and ADCC activity make it possible for benralizumab to be theoretically more powerful than mepolizumab and reslizumab in mediating a sustained control of type-2 inflammation. Therefore, the "dual-sword" modality of the therapeutic action of benralizumab should provide a more complete resolution of eosinophilic asthma. In fact, eosinophil depletion by benralizumab is associated with a decreased rate of asthma exacerbations, as well as with relevant improvements in symptom score, lung function, and quality of life. ${ }^{66,67}$ Of course, head-to-head trials should be performed to comparatively evaluate benralizumab with either mepolizumab or reslizumab, and these comparisons could gain great value if they are carried out in real-life

Table I Benralizumab: summary of the main pre-marketing clinical trials

\begin{tabular}{|c|c|c|c|}
\hline Authors & Duration & Dosage & Main results \\
\hline Laviolette et al $2013^{55}$ & 12 weeks & 100 and $200 \mathrm{mg}$ & Lower numbers of blood eosinophils \\
\hline Castro et al $2014^{58}$ & 52 weeks & 2,20 , and $100 \mathrm{mg}$ & Fewer asthma exacerbations, lower numbers of blood eosinophils \\
\hline Nowak et al $2015^{59}$ & 12 weeks & 0.3 and $\mathrm{I} \mathrm{mg} / \mathrm{kg}$ & Fewer asthma exacerbations, lower serum levels of ECP and EDN \\
\hline Park et al $2016^{57}$ & 52 weeks & 2,20 , and $100 \mathrm{mg}$ & Fewer asthma exacerbations, higher $\mathrm{FEV}_{\mathrm{I}}$ \\
\hline Bleecker et al $2016^{61}$ SIROCCO & 48 weeks & $30 \mathrm{mg}$ & Fewer asthma exacerbations, higher FEV \\
\hline FitzGerald et al $2016^{62}$ CALIMA & 56 weeks & $30 \mathrm{mg}$ & Fewer asthma exacerbations, higher $\mathrm{FEV}_{\mathrm{I}}$ \\
\hline Nair et al $2017^{63}$ ZONDA & 28 weeks & $30 \mathrm{mg}$ & Lower intake of oral corticosteroids, fewer asthma exacerbations \\
\hline Ferguson et al $2017^{64}$ BISE & 12 weeks & $30 \mathrm{mg}$ & Lower numbers of blood eosinophils \\
\hline
\end{tabular}

Abbreviations: ECP, eosinophilic cationic protein; EDN, eosinophil-derived neurotoxin; FEV , forced expiratory volume in I second. 
settings. An interesting meta-analysis referring to 10 trials and involving $>3,000$ patients was carried out by Cabon et al, with the aim of comparing the efficacy and safety of mepolizumab, reslizumab, and benralizumab in patients with severe eosinophilic asthma. ${ }^{68}$ The authors did not find any significant difference among these 3 drugs with regard to their ability to reduce asthma exacerbations, as well as to increase $\mathrm{FEV}_{1}$ and improve symptom control. Evident differences were not detected in the occurrence of adverse events induced by these biological treatments. However, this meta-analysis did not include Phase III studies referring to benralizumab and reslizumab. In this regard, it is noteworthy that the ZONDA trial showed that benralizumab lowered by $75 \%$ (versus baseline) the intake of oral corticosteroids, ${ }^{63}$ whereas the corticosteroid-sparing effect of mepolizumab consisted of a $50 \%$ decrease (versus placebo) in prednisone dosage, reported by the Phase III SIRIUS study. ${ }^{69}$ Moreover, the use of benralizumab could have further advantages. In this regard, a recent analysis of pooled results from SIROCCO and CALIMA studies have demonstrated that benralizumab was equally effective as add-on biological therapy in the treatment of both allergic and non-allergic eosinophilic asthma. ${ }^{70}$ An additional positive feature of benralizumab is its proven effectiveness even when administered Q8W, which can be very advantageous for improving patient adherence to treatment. Anyway, on the basis of its very good efficacy and safety profile, arising from many pre-marketing clinical studies, benralizumab seems to possess all the credentials necessary to become a cornerstone of the biological therapy of severe eosinophilic asthma.

\section{Disclosure}

The authors report no conflicts of interest in this work.

\section{References}

1. Pelaia G, Vatrella A, Busceti MT, et al. Cellular mechanisms underlying eosinophilic and neutrophilic airway inflammation in asthma. Mediators Inflamm. 2015;2015:879783.

2. Holgate ST, Wenzel S, Postma DS, Weiss ST, Renz H, Sly PD. Asthma. Nat Rev Dis Primers. 2015;1:15025.

3. Carr TF, Zeki AA, Kraft M. Eosinophilic and non-eosinophilic asthma. Am J Respir Crit Care Med. 2018;197(1):22-37.

4. Zhang X, Moilanen CE, Kankaanranta H. Enhancement of human eosinophil apoptosis by fluticasone propionate, budesonide, and beclomethasone. Eur J Pharmacol. 2000;406(3):325-332.

5. Pelaia G, Vatrella A, Busceti MT, et al. Molecular and cellular mechanisms underlying the therapeutic effects of budesonide in asthma. Pulm Pharmacol Ther. 2016;40:15-21.

6. Dunican EM, Fahy JV. Asthma and corticosteroids: time for a more precise approach to treatment. Eur Respir J. 2017;49(6):1701167.

7. Pazdrak K, Moon Y, Straub C, et al. Eosinophil resistance to glucocorticoid-induced apoptosis is mediated by the transcription factor NFIL3. Apoptosis. 2016;21(4):421-431.
8. Woodruff PG, Modrek B, Choy DF, et al. T-helper type 2-driven inflammation defines major sub-phenotypes of asthma. Am J Respir Crit Care Med. 2009;180(5):388-395.

9. Brusselle GG, Maes T, Bracke KR. Eosinophilic airway inflammation in non allergic asthma. Nat Med. 2013;19(8):977-979.

10. Walker JA, Barlow JL, McKenzie AM. Innate lymphoid cells: how did we miss them? Nat Rev Immunol. 2013;13(2):75-87.

11. Smith SG, Chen R, Kjarsgaard M. Increased numbers of activated group 2 innate lymphoid cells in the airways of patients with severe asthma and persistent airway eosinophilia. J Allergy Clin Immunol. 2016; 137(1):75-86.

12. Shakoory B, Fitzgerald SM, Lee SA, Chi DS, Krishnaswamy G. The role of human mast cell-derived cytokines in eosinophil biology. J Interferon Cytokine Res. 2004;24(5):271-281.

13. Hogan SP, Rosenberg HF, Moqbel R, et al. Eosinophils: biological properties and role in health and disease. Clin Exp Allergy. 2008;38(5): 709-750.

14. Lambrecht BN, Hammad H. The immunology of asthma. Nat Immunol. 2015;16(1):45-56.

15. Yanagibashi T, Satoh M, Nagai Y, Koike M, Takatsu K. Allergic diseases: from bench to clinic-contribution of the discovery of IL-5. Cytokine. 2017;98:59-70.

16. Molfino NA, Gossage D, Kolbeck R, et al. Molecular and clinical rationale for therapeutic targeting of interleukin-5 and its receptor. Clin Exp Allergy. 2012;42(5):712-737.

17. Varricchi G, Bagnasco D, Borriello F, et al. Interleukin-5 pathway inhibition in the treatment of eosinophilic respiratory disorders: evidence and unmet needs. Curr Opin Allergy Clin Immunol. 2016;16(2): 186-200.

18. Pelaia G, Vatrella A, Maselli R. The potential of biologics for the treatment of asthma. Nat Rev Drug Discov. 2012;11(12):958-972.

19. Gallelli L, Busceti MT, Vatrella A, Maselli R, Pelaia G. Update on anticytokine treatment for asthma. Biomed Res Int. 2013;2013:104315.

20. Fulkerson PC, Rothenberg ME. Targeting eosinophils in allergy, inflammation and beyond. Nat Rev Drug Discov. 2013;12(2):117-129.

21. Bel EH, ten Brinke A. New anti-eosinophil drugs for asthma and COPD: targeting the trait. Chest. 2017;152(6):1276-1282.

22. Pelaia C, Vatrella A, Busceti MT, et al. Severe eosinophilic asthma: from the pathogenic role of interleukin-5 to the therapeutic action of mepolizumab. Drug Des Devel Ther. 2017;11:3137-3144.

23. Pelaia G, Vatrella A, Busceti MT, et al. Role of biologics in severe eosinophilic asthma: focus on reslizumab. Ther Clin Risk Manag. 2016;12: 1075-1082.

24. Matera MG, Calzetta L, Rinaldi B, Cazzola M. Pharmacokinetic/ pharmacodynamic drug evaluation of benralizumab for the treatment of asthma. Expert Opin Drug Metab Toxicol. 2017;13(9):1007-1013.

25. Takatsu K, Tominaga A, Harada N, et al. T cell-replacing factor (TRF)/ interleukin-5 (IL-5): molecular and functional properties. Immunol Rev. 1988;102:107-135.

26. Milburn MV, Hassell AM, Lambert MH, et al. A novel dimer configuration revealed by the crystal structure at $24 \mathrm{~A}$ resolution of human interleukin-5. Nature. 1993;363(6425):172-176.

27. Takatsu K, Takaki S, Hitoshi Y. Interleukin-5 and its receptor system: implications in the immune system and inflammation. Adv Immunol. 1994;57:145-190.

28. Rossjohn J, McKinstry WJ, Woodcock JM, et al. Structure of the activation domain of the GM-CSF/IL-3/IL-5 receptor common $\beta$-chain bound to an antagonist. Blood. 2000;95(8):2491-2498.

29. Murphy JM, Young IG. IL-3, IL-5, and GM-CSF signaling: crystal structure of the human $\beta$-common receptor. Vitam Horm. 2006;74:1-30.

30. Pazdrak K, Stafford S, Alam R. The activation of the Jak-STAT 1 signalling pathway by IL-5 in eosinophils. J Immunol. 1995;155(1): 397-402.

31. Stout BA, Bates ME, Liu LY, Farrington NN, Bertics PJ. IL-5 and granulocyte-macrophage colony-stimulating factor acyivate STAT3 and STAT5 and promote Pim-1 and cyclin D3 protein expression in human eosinophils. J Immunol. 2004;173(10):6409-6417. 
32. Pazdrak K, Olszewska-Pazdrak B, Stafford S, Garofalo RP, Alam R. Lyn, Jak2, and Raf-1 kinases are critical for the antiapoptotic effect of interleukin-5, whereas only Raf-1 kinase is essential for eosinophil activation and degranulation. $J$ Exp Med. 1998;188(3):421-429.

33. Bousquet J, Chanez P, Lacoste JY, et al. Eosinophilic inflammation in asthma. N Engl J Med. 1990;323(15):1033-1039.

34. Howarth PH, Bradding P, Montefort D, et al. Mucosal inflammation and asthma. Am J Respir Crit Care Med. 1994;150(5 Pt 2):S18-S22.

35. Louis R, Lau LCK, Bron AO, Roldaan AC, Radermecker M, Djukanović R. The relationship between airways inflammation and asthma severity. Am J Respir Crit Care Med. 2000;161(1):9-16.

36. Gleich GJ. Mechanisms of eosinophil-associated inflammation. J Allergy Clin Immunol. 2000;105(4):651-663.

37. McBrien CN, Menzies-Gow A. The biology of eosinophils and their role in asthma. Front Med. 2017;4:93.

38. Pazdrak K, Schreiber D, Forsythe P, Justement L, Alam R. The intracellular signal transduction mechanism of interleukin 5 in eosinophils the involvement of lyn tyrosine kinase and the Ras-Raf-1-Mekmicrotubule-associated protein kinase pathway. J Exp Med. 1995; 181(5):1827-1834

39. Adachi T, Alam R. The mechanism of IL-5 signal transduction. Am J Physiol. 1998;275(3 Pt 1):C623-C633.

40. Takatsu K, Nakajima H. IL-5 and eosinophilia. Curr Opin Immunol. 2008;20(3):288-294.

41. Bates ME, Green VL, Bertics PJ. ERK1 and ERK2 activation by chemotactic factors in human eosinophils is interleukin 5-dependent and contributes to leukotriene C4 biosynthesis. J Biol Chem. 2000; 275(15):10968-10975

42. Pelaia G, Cuda G, Vatrella A, et al. Mitogen-activated protein kinases and asthma. J Cell Physiol. 2005;202(3):642-653.

43. Thompson-Souza GA, Gropillo I, Neves JS. Cysteynil leukotrienes in eosinophil biology: functional roles and therapeutic perspectives in eosinophilic disorders. Front Med. 2017;4:106.

44. Adachi T, Choudhuri BK, Stafford S, Sur S, Alam R. The differential role of extracellular signal-regulated kinases and p38 mitogen-activated protein kinase in eosinophil functions. J Immunol. 2000;165(4): 2198-2204.

45. Ip WK, Wong CK, Wang CB, Tian YP, Lam CW. Interleukin-3, -5 , and granulocyte macrophage colony-stimulating factor induce adhesion and chemotaxis of human eosinophils via p38 mitogen-activated protein kinase and nuclear factor- $\mathrm{KB}$. Immunopharmacol Immunotoxicol. 2005;27(3):371-393.

46. Sano M, Leff AR, Myou S, et al. Regulation of interleukin-5-induced $\beta 2$-integrin adhesion of human eosinophils by phosphoinositide 3-kinase. Am J Respir Cell Mol Biol. 2005;33(1):65-70.

47. Koike M, Nakamura K, Furuya A, Iida A, Anazawa H, Takatsu K, Hanai N. Establishment of humanized anti-interelukin-5 receptor $\alpha$ chain monoclonal antibodies having a potent neutralizing activity. Hum Antibodies. 2009;18(1-2):17-27.

48. Ghazi A, Trikha A, Calhoun WJ. Benralizumab-a humanized $\mathrm{mAb}$ to IL-5R $\alpha$ with enhanced antibody-dependent cell-mediated cytotoxicity-a novel approach for the treatment of asthma. Expert Opin Biol Ther. 2012;12(1):113-118.

49. Menzella F, Lusuardi M, Galeone C, Facciolongo N, Zucchi L. The clinical profile of benralizumab in the management of severe eosinophilic asthma. Ther Adv Respir Dis. 2016;10(6):534-548.

50. Ishino T, Pasut G, Scibek J, Chaiken I. Kinetic interaction analysis of human interleukin 5 receptor $\alpha$ mutants reveals a unique binding topology and charge distribution for cytokine recognition. J Biol Chem. 2004;279(10):9547-9556.

51. Kolbeck R, Kozhich A, Koike M, et al. MEDI-563, a humanized anti-IL-5 receptor $\alpha \mathrm{mAb}$ with enhanced antibody-dependent cell mediated cytotoxicity function. J Allergy Clin Immunol. 2010;125(6):1344-1353.

52. Shields RL, Lai J, Keck R, et al. Lack of fucose on human IgG1 N-linked oligosaccharide improves binding to Fc $\gamma$ RIII and antibody-dependent cellular toxicity. J Biol Chem. 2002;277(30):26733-26740.
53. Shinkawa T, Nakamura K, Yamane N, et al. The absence of fucose but not the presence of galactose or bisecting $\mathrm{N}$-acetylglucosamine of human IgG1 complex-type oligosaccharide shows the critical role of enhancing antibody-dependent cellular cytotoxicity. J Biol Chem. 2003; 278(5):3466-3473.

54. Busse WW, Katial R, Gossage D, et al. Safety profile, pharmacokinetics, and biologic activity of MEDI-563, an anti-IL-5 receptor a antibody, in a phase I study of subjects with mild asthma. J Allergy Clin Immunol. 2010;125(6): 1237-1244.

55. Laviolette M, Gossage DL, Gauvreau G, et al. Effects of benralizumab on airway eosinophils in asthmatic patients with sputum eosinophilia. J Allergy Clin Immunol. 2013;132(5):1086-1096.

56. Assa'ad A, Rothenberg ME. Eosinophilic asthma: insights into the effects of IL-5 receptor targeting. J Allergy Clin Immunol. 2013;132(5): 1097-1098.

57. Park HS, Kim MK, Imai N, et al. A phase 2a study of benralizumab for patients with eosinophilic asthma in South Korea and Japan. Int Arch Allergy Immunol. 2016;169(3):135-145.

58. Castro M, Wenzel SE, Bleecker ER, et al. Benralizumab, an antiinterleukin 5 receptor $\alpha$ monoclonal antibody, versus placebo for uncontrolled eosinophilic asthma: a phase $2 \mathrm{~b}$ randomized dose-ranging study. Lancet Respir Med. 2014;2(11):878-890.

59. Nowak RM, Parker JM, Silverman RA, et al. A randomized trial of benralizumab, an antiinterleukin 5 receptor $\alpha$ monoclonal antibody, after acute asthma. Am J Emerg Med. 2015;33(1):14-20.

60. Pham T, Damera G, Newbold P, Ranade K. Reductions in eosinophil biomarkers by benralizumab in patients with asthma. Respir Med. 2016; 111:21-29.

61. Bleecker ER, Fitzgerald JM, Chanez P, et al; SIROCCO study investigators. Efficacy and safety of benralizumab for patients with severe asthma uncontrolled with high-dosage inhaled corticosteroids and long-acting $\beta_{2}$-agonists (SIROCCO): a randomized, multicentre, placebo-controlled phase 3 trial. Lancet. 2016;388(10056):2115-2127.

62. FitzGerald JM, Bleecker ER, Nair P, et al; CALIMA study investigators. Benralizumab, an anti-interleukin-5 receptor $\alpha$ monoclonal antibody, as add-on treatment for patients with severe, uncontrolled eosinophilic asthma (CALIMA): a randomised, double-blind, placebo-controlled phase 3 trial. Lancet. 2016;388(10056):2128-2141.

63. Nair P, Wenzel S, Rabe KF, et al. Oral glucocorticoid-sparing effect of benralizumab in severe asthma. $N$ Engl J Med. 2017;376(25): $2448-2458$

64. Ferguson GT, FitzGerald JM, Bleecker ER, et al; ZONDA Trial Investigators. Benralizumab for patients with mild to moderate persistent asthma (BISE): a randomised, double-blind, placebo-controlled phase 3 trial. Lancet Respir Med. 2017;5(7):568-576.

65. Liu T, Wang F, Wang G, Mao H. Efficacy and safety of benralizumab in patients with eosinophilic asthma: a meta-analysis of randomized placebo-controlled trials. Front Med. Epub 2017 Oct 30.

66. Tan LD, Bratt JM, Godor D, Louie S, Kenyon NJ. Benralizumab: a unique IL-5 inhibitor for severe asthma. $J$ Asthma Allergy. 2016;9: $71-81$.

67. Khorasanizadeh M, Eskian M, Assa'ad CA, Rezaei N. Efficacy and safety of benralizumab, a monoclonal antibody against IL-5R $\alpha$, in uncontrolled severe asthma. Int Rev Immunol. 2016;35(4):294-311.

68. Cabon Y, Molinari N, Marin G, et al. Comparison of anti-interleukin-5 therapies in patients with severe asthma: global and indirect metaanalyses of randomized placebo-controlled trials. Clin Exp Allergy. 2017;47(1):129-138.

69. Bel EH, Wenzel SE, Thompson PJ, et al; SIRIUS investigators. Oral glucocorticoid-sparing effect of mepolizumab in eosinophilic asthma. N Engl J Med. 2014;371(13):1189-1197.

70. Chipps BE, Newbold P, Hirsch I, Trudo F, Goldman M. Benralizumab efficacy by atopy status and serum immunoglobulin $\mathrm{E}$ for patients with severe, uncontrolled asthma. Ann Allergy Asthma Immunol. Epub 2018 Jan 31 . 


\section{Publish your work in this journal}

Drug Design, Development and Therapy is an international, peerreviewed open-access journal that spans the spectrum of drug design and development through to clinical applications. Clinical outcomes, patient safety, and programs for the development and effective, safe, and sustained use of medicines are the features of the journal, which

has also been accepted for indexing on PubMed Central. The manuscript management system is completely online and includes a very quick and fair peer-review system, which is all easy to use. Visit http://www.dovepress.com/testimonials.php to read real quotes from published authors.

Submit your manuscript here: http://www.dovepress.com/drug-design-development-and-therapy-journal 